\title{
Probabilistic assessment of safety against dune retreat along the Northern-Holland coast
}

\author{
W. van Balen ${ }^{1}$, V. Vuik ${ }^{1}$ and S. van Vuren ${ }^{1}$ \\ ${ }^{1}$ HKV Consultants, Botter 11-29, 8232 JN Lelystad, The Netherlands, w.vanbalen@hkv.nl
}

\begin{abstract}
Coastal zone management is a multidisciplinary issue that can be assessed from multiple viewpoints such as safety, recreation, ecology and nature. A possible means for properly maintaining the various functions of the coast is sand nourishments along either the shoreface and/or the beach. To assess the influence of sand nourishments, the time-dependency of appropriate indicators of the various coastal functions can be analyzed.

HKV has conducted a study that focuses on the probability of failure for dune erosion, as an indicator for safety. For this purpose, the yearly JarKus measurements from the online OpenEarth-database are used. HKV has computed the probability of failure for dune erosion for the entire Dutch coast, from 1965 until 2010, using the dune erosion model DUROS+ and the probabilistic method FORM ('First Order Reliability Method'), as implemented in the package PC-Ring. This approach is closely related to the approach of the project Flood Risks in the Netherlands (FLORIS / VNK).

The current paper presents results of these computations, in relation to previous nourishment activities, for the region of NorthernHolland. These gained results can be used to further analyze the effectiveness of nourishments and can hence benefit future nourishment strategies by providing a decision supporting framework.
\end{abstract}

\section{INTRODUCTION}

The major part of the Dutch coast consists of dunes. The sandy dunes form a natural and flexibel sea defense that serves multiple purposes such as safety against flooding of the hinterland, recreation, nature, ecology, drinking water supply, et cetera. However, since the Dutch coast is liable to structural erosion, the multiple functions of the Dutch coast are permanently subject to coastal retreat as a morphologic threat.

In order to properly support the various coastal functions and to counteract the coastal retreat, it has been decided in 1990 to dynamically maintain the shoreline. Therefore, the coastal management strategy has ever since amounted to sand nourishments to achieve the aims following from the coastal functions. Such sand nourishments can either be applied as beach nourishments and as shoreface nourishments. From 2000, the strategy has been focused on maintaining the coastal fundament, based on volumetric arguments.

During the past decades, several studies have been conducted to understand the physical processes underlying dune resilience (cf. Vellinga [1986], Steetzel [1993]) and several models have been developed to simulate these, such as the 1D dune resilience model DUROS+ and its later adaptations, such as DUROSTA (Steetzel [1993]), and the 2D model XBeach (Roelvink et al., [2009]) that simulates dune erosion, overwash and breaching. For each type of model, the availability of measured data of either the bathymetry (as input) and the physical parameters (for calibration and validation) is of key importance.

This paper presents the results of the application of a straightforward 1D dune erosion model, within a probabilistic context, to the dunes along the coast of Northern-Holland (see figure 1). For this, 225 JarKus transects (cf. Rijkswaterstaat [2008]) have been subjected to a probabilistic analysis for dune resilience. The main objective of this investigation has been to image the interplay between sand nourishments and dune resilience. For that purpose, the transect data (available in the online database OpenEarth [Van Koningsveld et al., 2010]) with measurements from 1965 until 2010 have been used.

This investigation has been a part of a broader research program in which the entire dune coast of the Netherlands is considered. The final result is failure probabilities for the coast for 1965-2010.

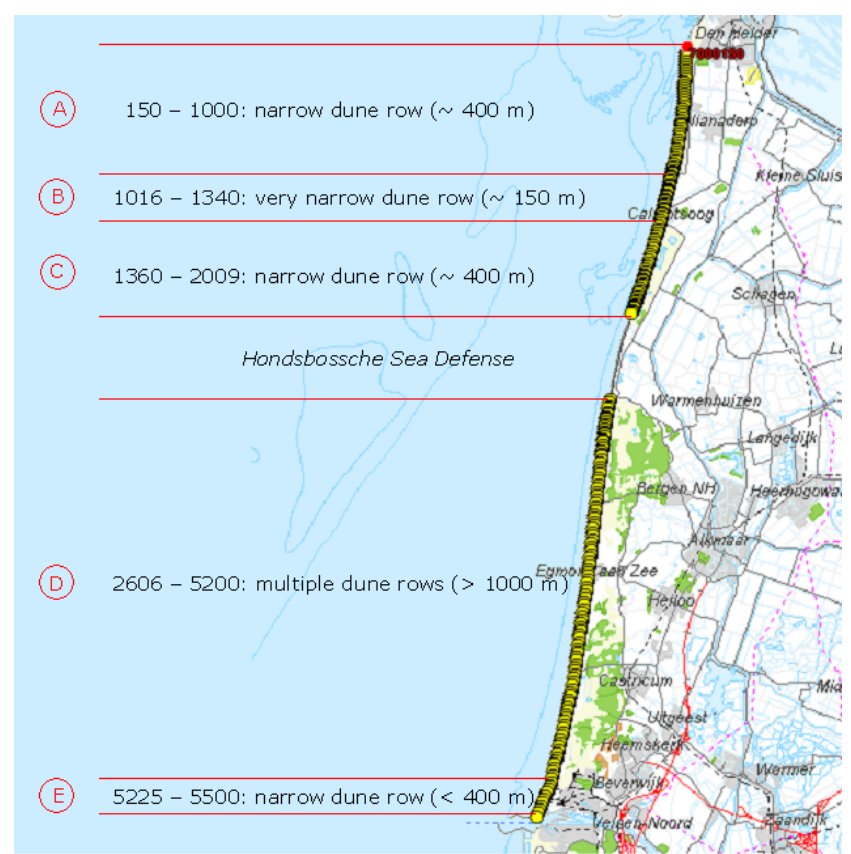

Figure 1. The Northern-Holland coast with distinction between six regions on the basis of dune width and number of dune rows. The yellow dots indicate transects for which a computation has been conducted. The numbers indicate the ID of a transect. 

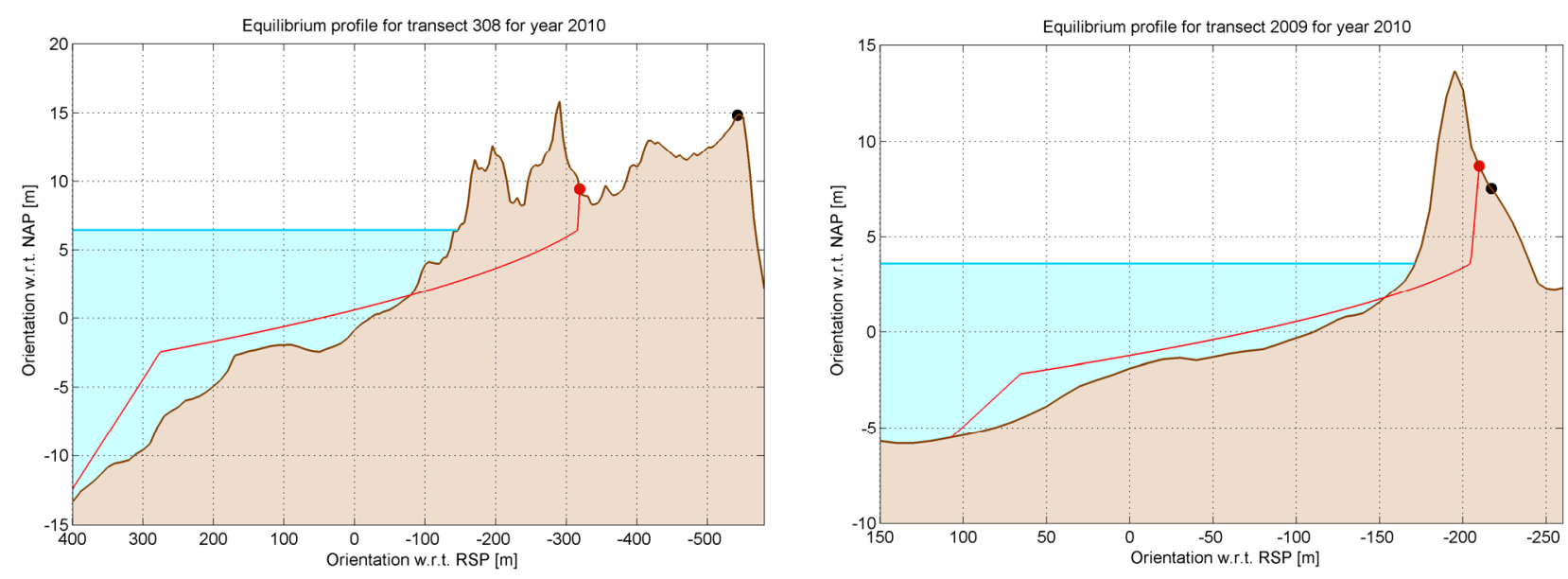

Figure 2. Dune profile and computed equilibrium profile of two JarKus transects in 2010. Left panel: transect 308 in the north of the Northern-Holland coastline; right panel: transect 2009 directly north of the Hondsbossche Sea Defense.

\section{METHODOLOGY}

In order to compute failure probabilities, the DUROS + model for dune erosion is used in combination with the probabilistic level II method FORM ('First Order Reliability Method') as it is implemented in the TNO software package PC-Ring (cf. [Vrouwenvelder \& Steenbergen, 2003], [Steenbergen et al., 2007]). The DUROS + model assumes a parabolically shaped equilibrium profile that develops during a storm (cf. [TAW, 2007]), thus ignoring time-dependent effects, but assessing a final state in which sand from the dune is deposited seawards.

The probabilistic method FORM is used to take uncertainties regarding the hydraulic loads as well as the strength of the dune into account. Basically, FORM is an optimization method with the constraint of a prevailing limit state function. Uncertainties with respect to dune erosion in this context are considered for key parameters like the wave height, the peak period, the grain size of the sand particles and the geometry.

A serious drawback of the DUROS+ model is the restriction of the dune profile to only a single dune row. In order to fulfill the resulting requirements, only the first dune row of the dune profile is taken into consideration. Figure 1 indicates that this restriction does not have consequences for dunes north of the Hondsbossche Sea Defence, whereas it does have consequences for dunes south of it. The latter category dunes are dunes with a considerable width, generally larger than $1 \mathrm{~km}$, with multiple dune rows.

The software package PC-Ring has been used in a Matlab-batch mode to compute the failure probabilities for each JarKus transect along the entire Dutch coast for the period 1965-2010.
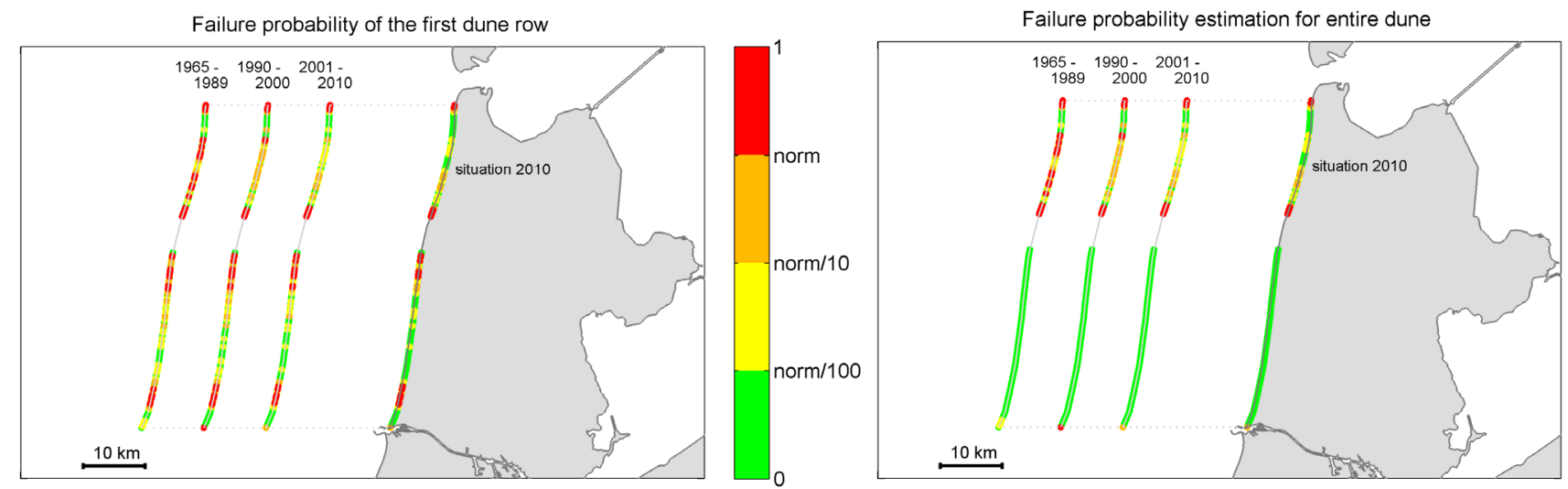

Figure 3. Failure probability of the first dune row (left panel) and estimated failure probability for the entire dune, including multiple dune rows. The failure probability (time-averaged) is normalized by a norm equal to $10^{-4}$ per year, being the safety standard for the hinterland of dikering 13. Three time windows are chosen: 1965 - 1989 (no nourishments), 1990 - 2000 (nourishment strategy based on maintaining the coast line) and 2001 - 2010 (nourishment strategy based on volumetric arguments). 
In total, about 75.000 computations have been carried out (1616 transects for 46 years), based on available profiles from OpenEarth for the entire Dutch coast. From this extensive dataset (actually a useful sequel of the study by Den Heijer et al. [2011]), the results for Northern-Holland are highlighted with the particular focus on the development of the failure probability for dune erosion and the role of sand nourishments.

\section{RESULTS}

As indicated in figure 1, dunes can consist of multiple dune rows. North of the Hondsbossche Sea Defense, the dunes contain only one row, whereas south of it, the dunes are wide $(>1 \mathrm{~km})$ and high (at some places $>30 \mathrm{~m}+\mathrm{NAP}$ ).

For brevity and conciseness, this paper therefore merely focuses on the northern part, i.e. regions A, B and C in figure 1. Along this region, the dunes are very narrow in the middle part (region $\mathrm{B}$ ).

An example of a relatively wide dune section is transect 308 , whereas an example of a very narrow one is transect 2009 (direct north of the Hondsbossche Sea Defense). The computed equilibrium profiles are shown in figure 2 . The calculated failure probabilities are $1.610^{-13}$ for transect 308 and $4.210^{-3}$ for transect 2009 , both on a yearly basis. These values can obviously directly be understood from the dune profiles. Also Den Heijer [2011] found such a high failure probability for transect 2009.

The results for the entire shoreline are shown in figure 3 . In this figure, distinction is made between four sets: the periods from 1965 - 1989 (no nourishments), from 1990 - 2000 (maintaining the shoreline) and from 2001 - 2010 (maintaining the coastal fundament). The situation for 2010 is shown as well.

For the three periods, the probabilities are time-averaged, based on the logarithm of their value. The values are furthermore normalized by the value of $1.010^{-4}$, being the normative safety standard for the hinterland (dikering 13). This normalization, which is basically arbitrary, is used to distinguish between four levels of safety.

In the left panel of figure 3, the failure probability is shown for the first dune row, whereas in the right panel of figure 3 , the estimated failure probability for the entire dune section is shown.
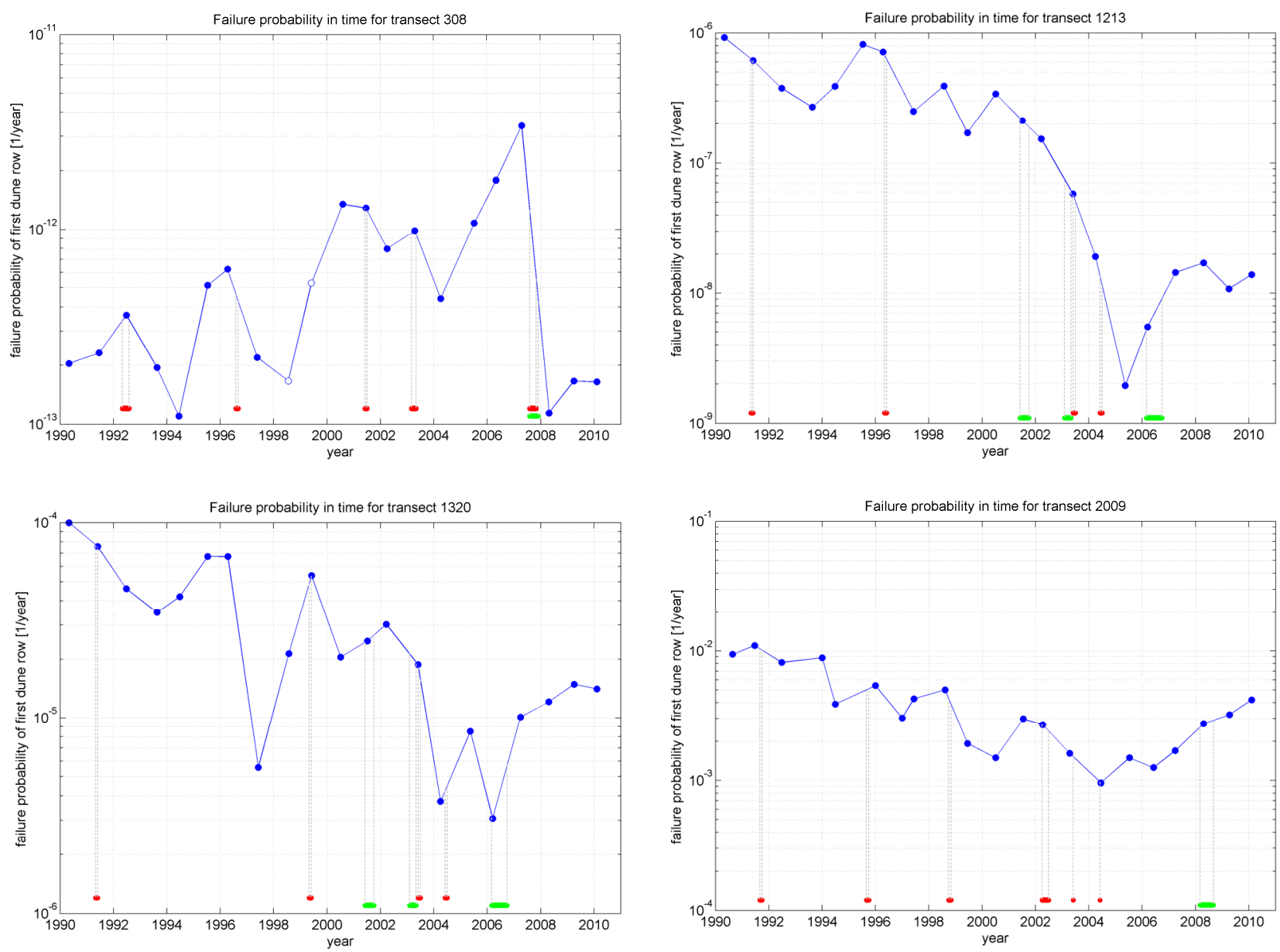

Figure 4. Development of the failure probability of the first dune row in time for four JarKus transects. In lexicographic ordering: transect 308, 1213, 1320 and 2009. The green lines indicate shoreface nourishment periods, the red lines indicate beach nourishment periods. Filled circles refer to correct convergence of the FORM-iteration, open circles refer to bad convergence behavior. 


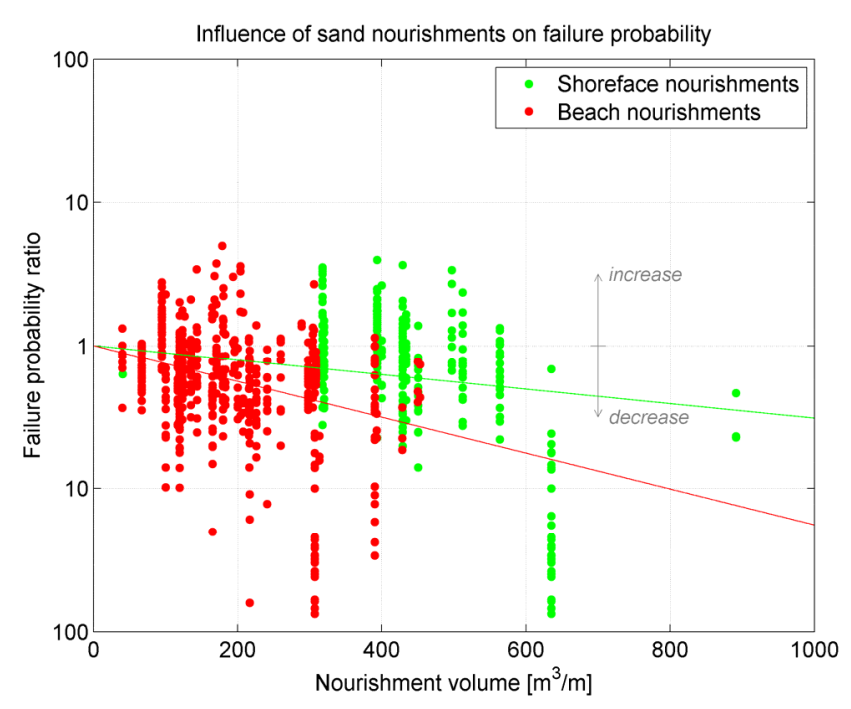

Figure 5. Failure probability ratio, defined as $P_{\text {year } j} / P_{\text {year } j-1}$, against the nourishment volume applied, showing the instantaneous effect of sand nourishments, i.e. the effect within one year after application. Green dots refer to shoreface nourishments, red dots refer to beach nourishments. The solid lines present an indication of the orientation of the data.

It is a sure thing that the failure probability of the first dune row is a conservative upper limit for the entire dune section. The basic result is that the part southern of the Hondsbossche Sea Defense can be considered as very safe, considering the huge body of dune mass beyond the first dune row. Generally, the failure probability tends to decrease in due time, which suggests a favorable effect of sand nourishments.

The regions that appear to be the weakest areas are the region in the very north (transects 150, 170 and 190) with failure probabilities of the order of $10^{-4}$ per year and the region just north of the Hondsbossche Sea Defense (transects 1940 until 2009) with probabilities of the order of $10^{-3}$ per year. The latter region consists of a relatively narrow dune row with a width sometimes smaller than $100 \mathrm{~m}$.

To gain more insight in the temporal development of the failure probability and, moreover, in the role of sand nourishments, the results for the last 20 years are shown in figure 4 . The green bars and red bars indicate periods of shoreface nourishments and beach nourishments, respectively. The points of time correspond with measuring times of the wet bathymetry part of the profile. Information on these times as well as on the nourishment times stem from the OpenEarth database.

From the data only four transects are elected for further analysis, for brevity: transects 308 (in the middle of region A, see figure 1), 1213 (region B), 1320 (region B) and 2009 (most southern point in region $\mathrm{C}$ ). The equilibrium profiles for transects 308 and 2009 are already shown in figure 2.

From the picture for transect 308 (figure 4), it can be derived that each nourishment has lead to a decrease of the failure probability, directly (instantaneously) in the year after application. Particularly, the nourishment in 2007 appears to be rather effective.
The effectiveness of the sand nourishments is also reflected in the picture for transect 1213 . The nourishments between 2000 and 2005 seem to be very effective with a probability decrease of a factor of about 100 .

Less effects are seen in the picture for transect 1320. Despite the nourishment between 1998 and 2008, only a decrease by a factor of about 10 is effectuated. The same observation holds for transect 2009 , be it even more pronouncedly.

To provide an impression of the instantaneous effects of the nourishments, figure 5 is included. This figure displays the failure probability ratio (defined as the probability in year $j$ divided by the probability in year $j-1)$ against the nourishment volume, for each transect where actually a nourishment has been applied.

For brevity, only the effects within one year are shown, which provides a first indication of the effectiveness of the nourishment. Obviously, only a first indication, since this figure discounts longterm, two-dimensional effects. This deficiency is definitely prone to improvement in the near future.

Nonetheless, figure 5 provides an interesting view on the results for the Northern-Holland part of the data. On average, a decrease in failure probability is gained within one year after nourishment, for both the beach nourishments and the shoreface nourishments.

Strict distinction between both types of nourishments can, however, not be made. Within this context, it should be mentioned that in many cases the location of application of a shoreface nourishment is situated outside the domain of the computed equilibrium profile. Moreover, shoreface nourishments are very likely to be important on supra-year timescales, which makes the causes of the effects less easily traceable.

In view of these deficiencies, an image is given of the bottom level difference between 2000 and 2005, on the one hand, and between 2005 and 2009, on the other hand, in figure 6 . In these figures, the four selected transects are depicted with a blue marker. These pictures are generated by means of subsequent interpolation and subtraction of $2 \mathrm{D}$ bathymetry files.

The strong decrease in failure probability at transect 308 in the year 2007 can directly be understood from the right panel of figure 6: a strong bottom level increase has taken place.

Something similar holds for transects 1213 and 1320, be it less pronouncedly: near the shore the bottom level has increased, whereas further from the shore a decrease and again an increase is seen in seaward direction.

The poor effectiveness of the nourishments near transect 2009 can directly be explained by figure 6 (left panel): in 2005 the bottom level hardly differs from the bottom level in 2000 .

\section{CONCLUSIONS AND OUTLOOK}

Dune retreat computations have been conducted using the 1D model DUROS+, in combination with the level II probabilistic method FORM. In total, about 75.000 computations have been carried out for the entire Dutch coast, for the last 46 years. In this paper, only some results for the shoreline of Northern-Holland (225 transects considered) are selected and presented.

The obtained results provide an image of the safety of the dune sections along Northern-Holland, by means of a probability of failure of the first dune row. The obtained distribution of the probability is used to identify weak spots. 


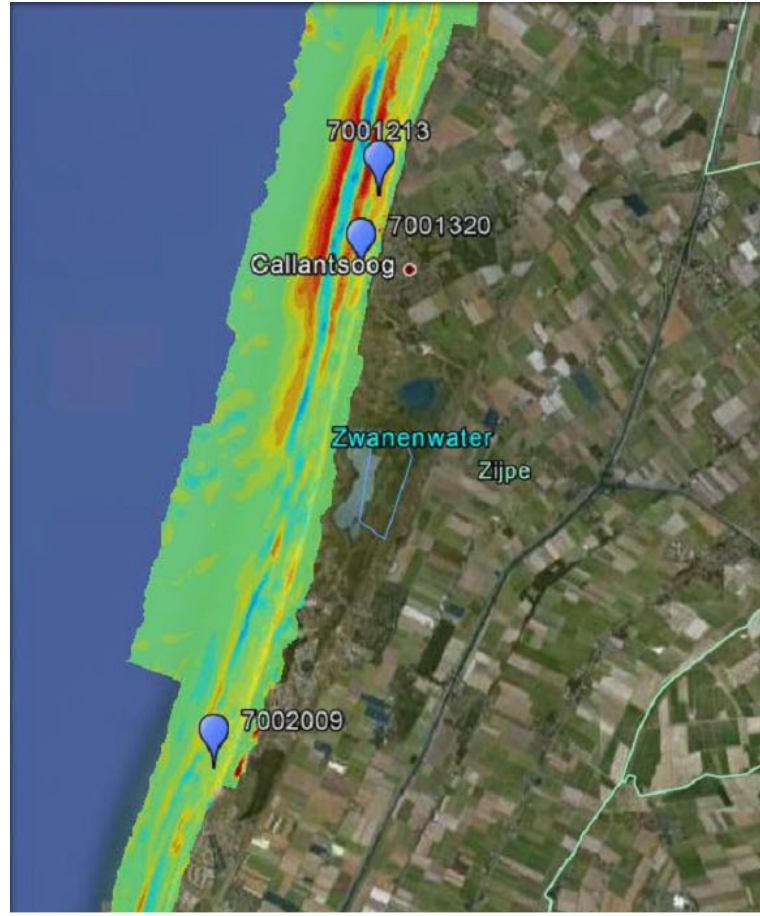

difference between 2005 en 2000

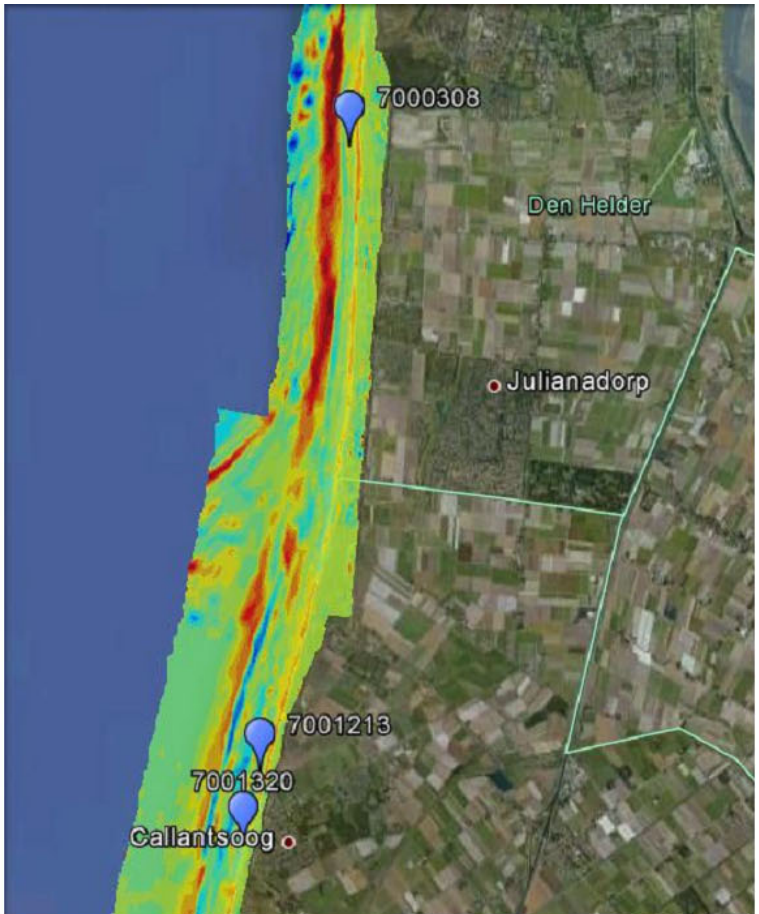

difference between 2009 en 2005

Figure 6. Left panel: bottom level changes in meters between 2005 and 2000 for the regions $B$ and $C$ (cf. figure 1). Right panel: bottom level changes in meters between 2009 and 2005 for the regions $A$ and B (cf. figure 1). The blue markers denote the JarKus transects for which the failure probability development in time is shown in figure 4.

By coupling of the gained results with available information on applied sand nourishments, an image has been sketched of the effectiveness of these nourishments. It turned out that sand nourishments in general, and beach nourishments in particular, on average enhance the safety level of the first dune row.

For the sake of conciseness, the presented results have been restricted to instantaneous effects, i.e. effects gained within one year. Moreover, the two-dimensional aspects have not extensively been addressed. Improvements on both shortcomings should be met in the near future to assess a more general picture of the effectiveness of sand nourishments.

After all, the gained results of about 75.000 computations can largely benefit the insight in the time development of the safety of the coast and its interplay with applied sand nourishments.

\section{ACKNOWLEDGEMENT}

This study has been carried out in cooperation with Deltares and Arcadis as a part of the project "KPP-B\&O Kust" (Kustlijnzorg), funded by Rijkswaterstaat Waterdienst.

\section{REFERENCES}

Heijer, C. den, Baart, F., Koningsveld, M. van, Assessment of dune failure along the Dutch coast using a fully probabilistic approach, Geomorphology (2011), doi:10.1016/j.geomorph. 2011.09.010.
Koningsveld, M. van, Boer, G.J. de, Baart, F., Damsma, T., Heijer, C. den, Geer, P. van, Sonneville, B. de, 2010. OpenEarth - inter-company management of: data, models, tools \& knowledge. Proceedings WODCON XIX Conference. Beijing, China.

Rijkswaterstaat, 2008. The yearly coastal measurements (De JAaRlijkse KUStmetingen (JARKUS)). (in Dutch)

Roelvink, D., Reniers, A., van Dongeren, A., van Thiel de Vries, J., McCall, R., Lescinski, J., 2009. Modelling storm impacts on beaches, dunes and barrier islands. Coastal Engineering 56, 1133-1152.

Steenbergen, H.M.G.M., Vrouwenvelder A.C.W.M., and Koster T., Theoriehandleiding PC-Ring Versie 5.0 Deel A: Mechanismenbeschrijvingen. TNO, 2007-D-Rxxxx/A, september 2007. (in Dutch)

Steetzel, H. J., 1993. Cross-shore Transport during Storm Surges. Ph.D. thesis, Delft University of Technology, also published as: Delft Hydraulics communication, no. 476.

TAW. Technische Rapport Duinafslag - Beoordeling van de veiligheid van duinen als waterkering ten behoeve van Voorschrift Toetsen op Veiligheid 2006. WL | Delft Hydraulics, TUDelft en Alkyon, H4357, mei 2007. (in Dutch)

Vellinga, P., 1986. Beach and Dune Erosion during Storm Surges. Ph.D. thesis, Delft University of Technology, also published as: Delft Hydraulics communications, no. 372, 1986.

Vrouwenvelder, A.C.W.M., and Steenbergen, H.M.G.M. Theoriehandleiding PC-Ring Versie 4.0 Deel C: Rekentechnieken. TNO, 2003-CI-R0022, april 2003. (in Dutch) 